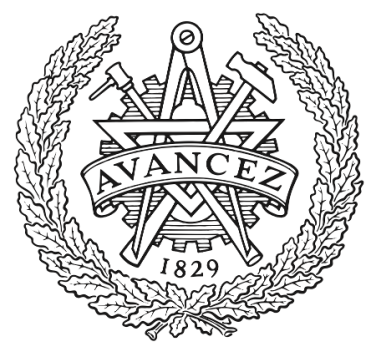

CHALMERS

UNIVERSITY OF TECHNOLOGY

\title{
A Tactical Demand-Supply Planning Framework to manage Complexity in Engineer-to-Order Environments: Insights from an in-depth [case study
}

Downloaded from: https://research.chalmers.se, 2023-04-26 06:56 UTC

Citation for the original published paper (version of record):

Shurrab, H., Jonsson, P., Johansson, M. (2022). A Tactical Demand-Supply Planning Framework to manage /Complexity in Engineer-to-Order

Environments: Insights from an in-ddepth |case study. Production Planning and Control, 33(5):

462-479. http://dx.doi.org/10.1080/09537287.2020.1829147

N.B. When citing this work, cite the original published paper. 


\title{
A tactical demand-supply planning framework to manage complexity in engineer-to-order environments: insights from an in-depth case study
}

\author{
Hafez Shurrab , Patrik Jonsson \& Mats I. Johansson
}

To cite this article: Hafez Shurrab, Patrik Jonsson \& Mats I. Johansson (2020): A tactical demand-supply planning framework to manage complexity in engineer-to-order environments: insights from an in-depth case study, Production Planning \& Control, DOI: 10.1080/09537287.2020.1829147

To link to this article: https://doi.org/10.1080/09537287.2020.1829147
(C) 2020 The Author(s). Published by Informa UK Limited, trading as Taylor \& Francis Group.

Submit your article to this journal $\asymp$

View related articles こ

\section{à}

Published online: 21 Oct 2020.

Шll Article views: 524

View Crossmark data $\nearrow$

Citing articles: 1 View citing articles ¿ 


\title{
A tactical demand-supply planning framework to manage complexity in engineer-to-order environments: insights from an in-depth case study
}

\author{
Hafez Shurrab (D), Patrik Jonsson (D) and Mats I. Johansson \\ Department of Technology Management and Economics, Chalmers University of Technology, Gothenburg, Sweden
}

ABSTRACT

The challenging demand-supply balancing in engineer-to-order (ETO) environments is often attributed to complexity. This study expands the understanding of managing complexity to obtain demand-supply balancing, focussing on the tactical planning logic of the order fulfilment process. An in-depth single case study was conducted and data describing the order fulfilment process at a construction company were collected and analysed. Findings suggest a tactical-level planning process framework, incorporating nine key decisions and three crucial activities, and their potential complexity-reducing and complexity-absorbing impact. The study contributes to the theoretical discussion of complexity in management practices, linking demand-supply balancing as a performance measure. The findings guide practitioners in ETO settings on anticipating potential medium-term consequences of key decisions on capacity. This emphasises the need of proper IT support to apply knowledge generated from previous projects and conduct comprehensive and robust scenario-based analyses.
ARTICLE HISTORY

Received 15 July 2019

Accepted 20 September 2020

\section{KEYWORDS}

Order fulfilment process; tactical planning; engineerto-order; complexity; case study

\section{Introduction}

Fulfilling demand in engineer-to-order (ETO) supply chains (SCs) requires engineering and production readiness to meet potential customisation requirements, which are not visible until customers publish order requests (Gosling, Hewlett, and Naim 2017). This and other contextual factors increase the SC complexity due to increased amounts of details and elevated levels of uncertainty that must be addressed (Birkie and Trucco 2016).

ETO product architectures allow countless customisation and modular configurations that require various levels of production flexibility (Shurrab, Jonsson, and Johansson 2020). Such response options to the ETO SC needs proliferate as the freedom to propose and design solutions to customerstypically given to sales and engineering functions, respectively-increases (Cannas et al. 2020). Moreover, winning customer orders in the ETO (typically tender-based) SCs is a probability (Hicks, McGovern, and Earl 2000). Here, customers substantially vary in organisation size, tendency to request changes after agreements, and knowledgeability of technical and functional needs (Cannas et al. 2020). Such high complexity challenges demand-supply (DS) balancing as identifying the capacity needs is subject to significant uncertainty that limits the accuracy of estimated capacity requirements and timeliness of required decisions (Shurrab, Jonsson, and Johansson 2020).

The uniqueness driven by the influx of ETO customer orders entails regular extensive adaptations to the underlying production infrastructure (e.g. machines, equipment, facility layouts, and material handling); such adaptions are time consuming. This makes production planning at an aggregate medium-term (tactical) level necessary to early detect potential shortages in, for instance, critical competences (Giebels 2000) which are often challenging to acquire at short notice (Cooper and Budd 2007). Therefore, failure to identify types and timings of critical capacity constraints in ETO settings typically leads to DS balancing failure (Shurrab, Jonsson, and Johansson 2020). Thus, SC complexity in ETO contexts makes tactical DS balancing both crucial and difficult to manage.

DS balancing is typically considered as a role of tactical planning (see Jonsson and Holmström 2016; Kristensen and Jonsson 2018; Pereira, Oliveira, and Carravilla 2020). Literature and process frameworks, e.g. on sales and operations planning (S\&OP), explain and guide the design and management of tactical-level DS balancing (e.g. Grimson and Pyke 2007). However, this literature is contextually weak and does not provide helpful ETO-specific explanations or frameworks (Kristensen and Jonsson 2018).

Some studies partially explain the impact of tactical planning on DS balancing in ETO settings through testing objective functions that minimise costs (e.g. Gademann and Schutten 2005) or timespans (e.g. Nobibon et al. 2015), or maximise revenues (e.g. Alfieri, Tolio, and Urgo 2011). Carvalho, Oliveira, and Scavarda (2015) included a broader scope, focussing on more variables. Such quantitative contributions provide useful and heterogeneous insights into 
Table 1. Engineering decoupling configurations.

\begin{tabular}{|c|c|c|c|}
\hline Decoupling point & $\begin{array}{l}\text { Activities after the entry of } \\
\text { customer orders }\end{array}$ & Starting point after order entry & Typical input from customers \\
\hline Research & Concept development & $\begin{array}{l}\text { Math or science: academic results } \\
\text { Engineering: problem briefs and codes }\end{array}$ & $\begin{array}{l}\text { Feasibility specifications with open brief } \\
\text { Constraint specification and approvals }\end{array}$ \\
\hline Develop & $\begin{array}{l}\text { Development of codes, standards, } \\
\text { and principles }\end{array}$ & $\begin{array}{l}\text { Develop (or integrate) codes: updating } \\
\text { of (or departure from) codes } \\
\text { or standards }\end{array}$ & $\begin{array}{l}\text { Tendering documentation and } \\
\text { negotiation }\end{array}$ \\
\hline Design & Designing detailed product specifications & Codes, standards, case studies & \\
\hline Modify & $\begin{array}{l}\text { Major (or minor) modifications of } \\
\text { existing designs to change technical } \\
\text { or functional (or superficial) } \\
\text { characteristics }\end{array}$ & Adapted design: building systems & Requirements and technical approvals \\
\hline Combine & $\begin{array}{l}\text { Combining a set of pre-defined } \\
\text { design options }\end{array}$ & $\begin{array}{l}\text { Finalised (or complete) design: module } \\
\quad \text { (or approved) designs }\end{array}$ & Order with project documentation \\
\hline
\end{tabular}

limited scopes of tactical-level planning. They simplify the tactical planning problem by focussing on a few fragmented activities and decisions. Addressing all important tactical-level planning activities and decisions is crucial for proper DS balancing (Shurrab, Jonsson, and Johansson 2020). To extend the understanding of tactical-level DS balancing in ETO settings, there is, thus, a need to holistically conceptualise the underlying planning activities and decisions that serve as a response to the ETO SC complexity, and understand how these activities and decisions manage SC complexity.

Galbraith's (1977) information processing logic provides a basis to study the SC complexity constraining DS balancing. Accordingly, decisions entailing reduced amounts of detail and levels of uncertainty reduce the complexity constraining DS balancing. Meanwhile, decisions entailing increased capacity to process details and uncertainties absorb the complexity constraining DS balancing. According to Fernández Campos, Trucco, and Huaccho Huatuco (2019), extant complexity research does not sufficiently support practitioners in dealing with complexity. Holistic studies that provide an indepth understanding of SC complexity management to achieve a business objective are needed. Therefore, this study aims at expanding the understanding of managing SC complexity in an ETO environment to achieve the business objective of DS balancing. The study sets forth the following research question:

- RQ: How does the tactical-level planning process contribute to reducing and absorbing the SC complexity that constrains the ability to balance customer demand and supply capacity in an ETO setting?

Several studies associate the order fulfilment process with tactical planning in ETO settings as this process aims at aligning sales opportunities with the strategic business objectives, and identifying corresponding supply and capacity needs within a medium-term time horizon (e.g. Giebels 2000; Hans et al. 2007; Carvalho, Oliveira, and Scavarda 2015; Shurrab, Jonsson, and Johansson 2020). Therefore, this study focuses on the order fulfilment process. The construction industry is a highly relevant ETO sector, where DS balancing is particularly complex (Shurrab, Jonsson, and Johansson 2020). The authors had the opportunity to carry out a 2-year research collaboration with a leading construction company. Further, the exploratory nature of the research questions and the need of achieving an in-depth knowledge of a wide set of interrelated activities and decision logics motivate a single case-study design.

\section{Literature review}

\subsection{ETO planning context}

Broadly, planning and controlling production, and managing capacity depend on the position of the customer order decoupling (COD) point (Bertrand and Muntslag 1993; Olhager, Rudberg, and Wikner 2001; Earl, Song, and Hicks 2003; Olhager 2010). COD settings influence the amount of work that firms perform before (i.e. forecast-driven activities) and after (i.e. customer order-driven activities) the receipt of customer requests (Giesberts and Tang 1992; Hoekstra and Romme 1992).

ETO settings have the highest ratio of customer orderdriven to forecast-driven activities compared to other decoupling settings-e.g. make-to-stock (MTS), assemble-to-order (ATO), or make-to-order (MTO) settings-due to the postponement of engineering, which entails substantial planning complexity (Wikner and Rudberg 2005). The contextual variations within ETO-oriented businesses result in different COD configurations, as proposed by Gosling, Hewlett, and Naim (2017). Cannas et al. (2019) further developed a twodimensional (2D) COD framework addressing engineering and production configurations as separated process flows with underlying sub-flows. Table 1 combines insights from the works of Cannas et al. (2019) and Gosling, Hewlett, and Naim (2017) describing common engineering decoupling configurations.

The generic production decoupling configurations refer to the initial production activities after the entry of customer orders: purchasing raw materials, production of components and subassemblies, using some components in stock and making or purchasing the customised components to finalise assembly, final assembly using components and subassemblies in stock, and delivery of finished products from stock (Cannas et al. 2019).

Cannas et al. (2020) proposed contextual factors stemming from market, product, and process that determine the 


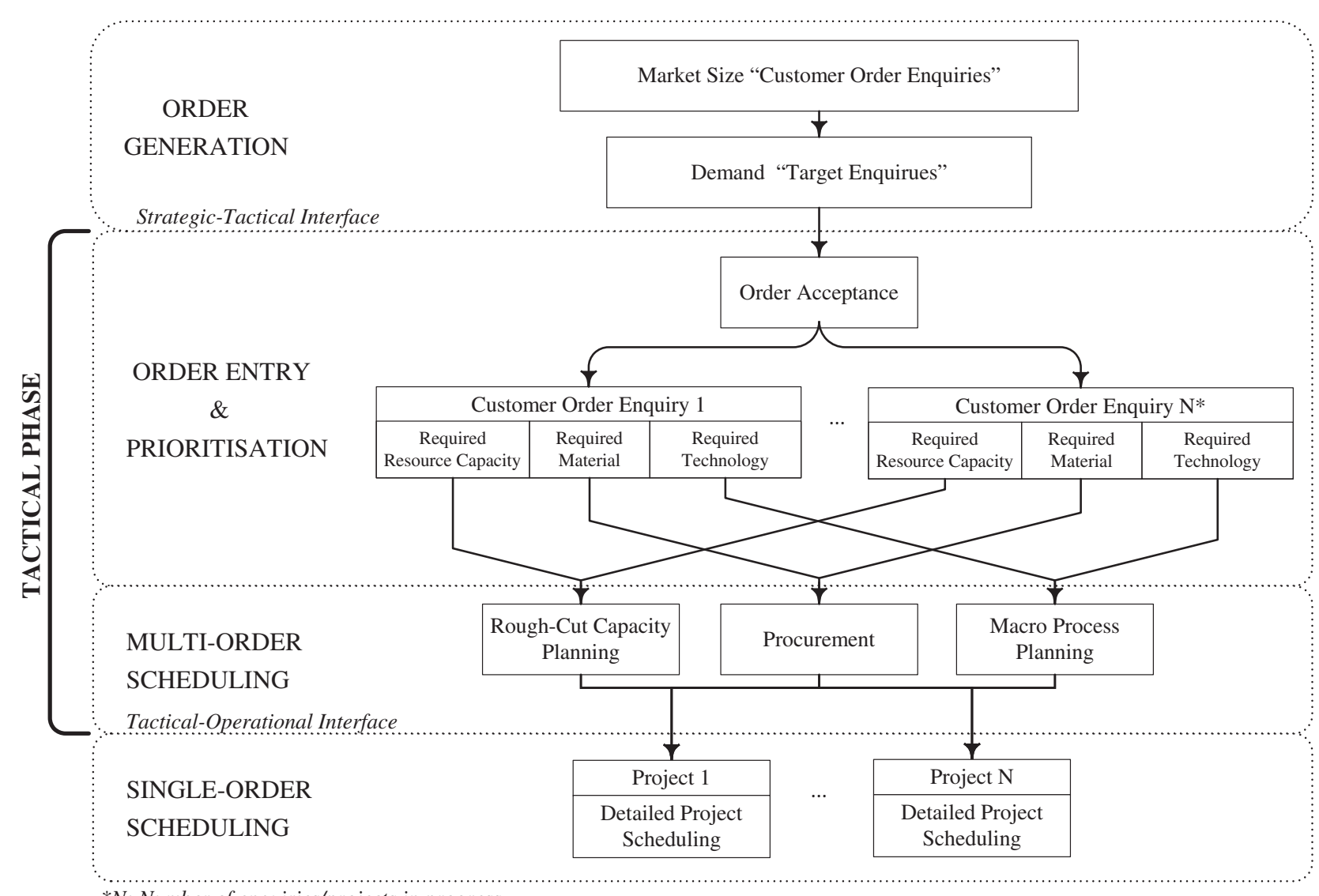

*N: Number of enquiries/projects in progress

Figure 1. The order acceptance phase within the order fulfilment process.

effectiveness of order fulfilment strategies and 2D-COD positions. A generic assumption drawn from these works is that the less work engineered and made to forecast, the greater the complexity companies must manage (reduce or absorb) through tactical-level planning processes.

\subsection{Tactical planning in ETO organisations}

Tactical planning coordinates demand and supply planning among relevant functions. One example of a tactical-level planning process is S\&OP. This enables managers of functional units to jointly balance demand and supply so that operations fulfil the overall business objectives (e.g. Oliva and Watson 2011). Extant ETO research proposes four tactical-level planning processes corresponding to the S\&OP subprocesses. These are order acceptance, rough-cut capacity planning (RCCP), procurement, and macro process planning (Hans et al. 2007). Unlike S\&OP, the literature on these individual processes lacks comprehensive coordination across functions that explain underlying planning activities and decisions associated with DS balancing. According to Fleischmann and Meyr (2003), establishing integrated planning processes requires clear descriptions of alternatives, objectives, and constraints, and adequate use of optimisation algorithms (Kjellsdotter Ivert and Jonsson 2014).

Another research stream suggests process reference frameworks concerning order fulfilment processes to ETOoriented companies, regardless of the decoupling settings in question (e.g. Weber et al. 2000; Adrodegari et al. 2015).
Order fulfilment processes serve as an available-to-promise function, responding to customer enquiries based on lead time agreements and material and capacity availabilities (Olhager 2010). The proposed order fulfilment process frameworks provide rich insights into detailed activities and decisions, starting with tender requests until final cost assessment upon order completion. Yet, operational- and tactical-level activities and decisions are not differentiated. Doing so is central for practitioners to appropriately address medium-term DS balancing issues instead of keeping on firefighting near-term problems.

According to Giebels (2000), tactical planning in ETO settings starts when customer enquiries are selected to conduct available-to-promise assessments within order acceptance. Order acceptance corresponds to the order entry and prioritisation stage as referred to in Day's (1994) generic order fulfilment process. After accepting strategically fit customer orders, planners conduct multi-order RCCP, procurement, and macro process planning to identify capacity, material, and technology needs (Giebels 2000; Hans et al. 2007). In Day's (1994) model, these processes correspond to order scheduling, which seems to partially fall into the operational phase concerned with detailed short-term single-order scheduling. Figure 1 adapts the hierarchical structure of Hans et al. (2007) and Giebels (2000), and the fulfilment process of Day (1994) into a conceptual framework for the main tactical-level planning activities within the order fulfilment process in ETO settings. 
Giebels (2000) identified three main objectives of RCCP including verifying manufacturing capabilities, determining delivery dates for enquiries, and analysing expected margins at a multi-project level. Verifying manufacturing capabilities occurs within macro process planning by assessing the ability of resource combinations to deliver orders. Macro process planning entails selecting manufacturing processes and assessing manufacturability. Micro process planning comprises selecting and sequencing operations and generating optimal process plans (Cay and Chassapis 1997).

Macro process planning specialists usually possess relevant in-depth engineering knowledge, which enables effective RCCP (i.e. allocating technological and logistics capacity, determining routeing, and conducting outsourcing). This helps to effectively absorb demand and supply complexity. Having sufficient information about the master production schedule, routings, and processing times at a tactical level is difficult in practice without integrating macro process planning into tactical planning (Giebels 2000).

Estimating delivery dates requires detailed analysis of engineering and production workloads and lead times. Engineering determines product and production designs, material, and technologies. Planning sourcing and purchasing of external contributions (e.g. consultants and subcontractors) occurs through procurement to complement, enhance and support engineering and production given the constraints on internal resources. Allocating or loading resources aims at identifying capacity issues early and triggering process planning when necessary. However, for companies performing minimal engineering and production to forecast, routings and processing durations of engineering activities lack standard references (Cannas et al. 2019). To deal with such contexts imposing increasing complexities in concurrent engineering workflows, Ventroux, Marle, and Vidal (2018) suggested reshuffling projects between and within the organisations (resources) to maximise the number of interactions supporting critical decision-making and action processes.

Determining delivery due dates also requires lead times of internal and external engineering and production activities. The latter requires more operational data like order priority, amount of work in process, routeing and batching (Giebels 2000). Once determined, estimating margins becomes possible. To avoid sub-optimisation, making tradeoffs at a multi-project level between the acquisition cost of non-regular capacity (e.g. subcontracting) and gained performance benefits is necessary (Gademann and Schutten 2005). Fulfilling each incoming customer order needs customised and timely plans for buying material, technology, transportation, and extra capacity (Olhager 2010). In certain ETO settings, strategic partnering that offers cost, quality and flexibility benefits is difficult to apply (Sabolová and Tkác 2015). As such, sourcing and purchasing from large supply bases increases the required coordination.

\subsection{Complexity in ETO settings}

As discussed earlier, an increase in the engineering and production complexity associated with the order fulfilment activities after order entry entails greater complexity of ETO SCs. To conceptually address SC complexity, this study departs from the framework of Bozarth et al. (2009), which describes drivers that generate detail (or structural) complexity and dynamic complexity. Senge (1998) related structural complexity to system structures represented by the number of variables embedded in a system. They defined dynamic complexity as being the 'situations where cause and effect are subtle, and where the effects over time of interventions are not obvious' (71). The dynamic complexity construct is closely related to uncertainty. Serdarasan (2013) argued that uncertainty concerned with time and randomness represent the essence of dynamic complexity. According to Galbraith (1977, 36-37), 'uncertainty is the difference between the amount of information required to perform the task and the amount of information already possessed by the organisation'. Therefore, higher uncertainty drives decision makers to process more information to execute tasks and achieve a given level of performance.

Many recent complexity studies have also used the framework of Bozarth et al. (2009) as a foundational component (e.g. Serdarasan 2013; Aitken, Bozarth, and Garn 2016; Birkie and Trucco 2016; Turner, Aitken, and Bozarth 2018; Fernández Campos, Trucco, and Huaccho Huatuco 2019), since it offers a comprehensive overview, and can help in categorising the complexity drivers based on their source. This allows relating the drivers to demand or supply serving as high-level sources of complexity, which makes relating the impact of complexity to DS balancing possible. At the same time, the framework explicates SC complexity drivers at a suitable level of generalisable detail.

According to Bozarth et al. (2009), the drivers of SC complexity are either downstream, internal manufacturing, or upstream drivers. Downstream drivers stem from the demand side. These drivers include the number of customers, heterogeneity in customer needs, and demand variability. In ETO SCs that need increased engineering and production activities after order entry, customer needs are extremely heterogeneous and demand shows high variability (Cannas et al. 2020).

Internal manufacturing drivers and upstream drivers stem from the supply side. These drivers include the number and mix of products, components and suppliers; constraints enforcing low-volume batching and project-based manufacturing; manufacturing schedule instability; length and reliability of supplier lead times; and SC globalisation. Most, if not all, of these drivers are highly represented in ETO SCs (Gosling and Naim 2009).

Cannas et al. (2020) describe complementary contextual (market-, product and process-related) variables of high relevance to order fulfilment in ETO settings. This further expands the list of drivers. As proposed and summarised in Table 2, the related variables encompass the organisation size of customers, customer's product knowledge and order change behaviour, technology maturity, modularity and customisability of product structures, sales and engineering process structures, and cross-functional interfaces. 
Table 2. SC complexity drivers in ETO settings.

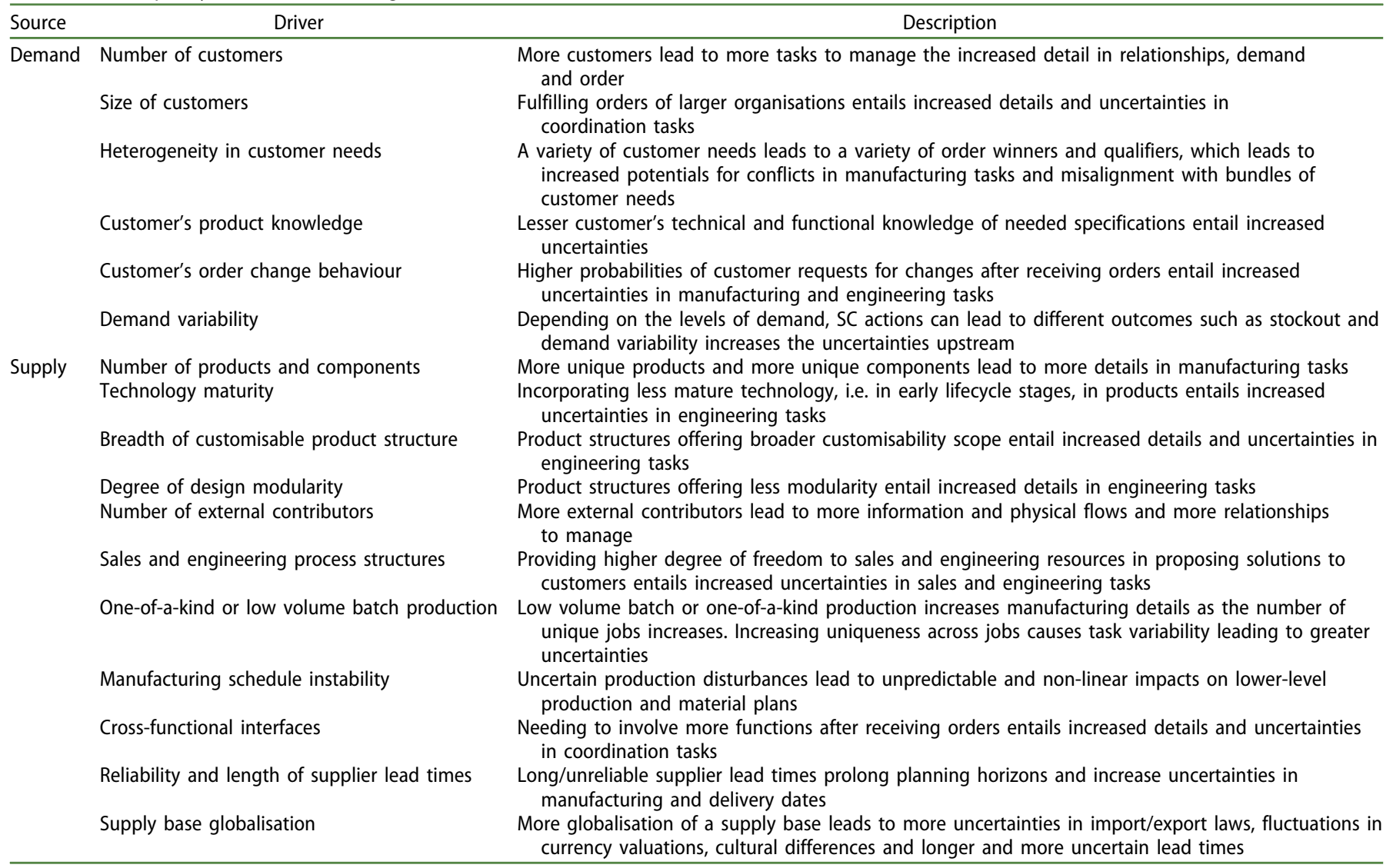

Regardless of the complexity drivers, Turner, Aitken, and Bozarth (2018) recommended distinguishing between strategic and non-strategic (or dysfunctional) complexity since reducing strategic complexity is either infeasible or disadvantageous to the business. In this respect, previous studies identify two main approaches including non-strategic complexity reduction (e.g. Rauch, Dallasega, and Matt 2018) and strategic complexity absorption (e.g. Serdarasan 2013). Reducing complexity is possible through reducing information processing. Absorbing complexity is possible through increasing the information processing capacity (Galbraith 1977). This study applies the information-processing logic of these two approaches to inductively identify the tactical-level decision impact on complexity.

\section{Method}

\subsection{Research approach and research site}

This study adopts an embedded single-case research design, addressing the order acceptance phase of the order fulfilment process as the first-level and incoming customer orders as the second level. Although the generalisability of findings resulting from single-case studies is questionable, single cases are empirically rich, context specific, and holistic. This allows for in-depth analysis and valuable contributions to theory building (Stake 2000). Extant tactical planning research concerning ETO SCs provides limited insights into the DS balancing phenomenon. Thus, exploring the impact of related activities on the structural and dynamic complexity stemming from demand and supply requires substantial indepth analysis.

According to Yin (2017), the goal of single-case studies is not to extrapolate probabilities and statistical generalisations, but to rather expand analytic generalisations to theoretical propositions, not to populations. As described in Section 2, to be effective, the managerial approaches to which tactical planning belongs must fulfil the requirements of the 2D-COD position in question (Cannas et al. 2019). Usually, the assortments ETO-oriented companies offer may include product families with various 2D-COD configurations. Empirical evidence from the work of Gosling, Hewlett, and Naim (2017) shows that the construction industry deals with a broad set of customer orders representing several engineering decoupling configurations (research-, develop-, design-, modifyand combine-to-order). This allows for greater generalisability of case results.

The construction product families are characterised by deep structures with extremely broad customisation scopes. Construction projects embed considerable uniqueness where job-shop and project-based manufacturing processes are highly needed (Gosling et al. 2015). In construction SCs, the focal actors that highly influence DS balancing are general contractors. General contractors play the role of original equipment manufacturers (OEMs) in SCs by selecting orders and suppliers, deciding on execution methods given a set of requirements, and leading the order fulfilment process towards on-time and within-budget deliveries (Hicks, 
McGovern, and Earl 2001). Therefore, the selected case here is a large Swedish general contractor (SGC), which is a major player in the Swedish housing market.

According to Yin (2017), the rationale for selecting single cases may be because they are revelatory, common, and longitudinal cases. Revelatory cases offer an opportunity to observe and analyse a phenomenon previously inaccessible. Common cases capture conditions of a regular situation to understand social processes related to theoretical interests. Longitudinal cases cover trends over extended periods to follow a developmental course of interest. To some extent, such rationales apply to the selected case. SGC dedicated a project to study how to develop advanced planning systems within the order fulfilment process to maximise critical resource utilisation when selecting orders, which is a tactical-level planning problem (Carvalho, Oliveira, and Scavarda 2015). Since this unique project required a comprehensive investigation of the current state of the common order fulfilment process at the company over an elongated period (September 2016 to September 2018), the authors had a revelatory opportunity to observe and analyse DS balancing through participating in the project as researchers.

\subsection{Interview protocol}

According to Yin (2017), single-case designs must maximise access to empirical evidence to balance their potential vulnerability against misrepresentation. Therefore, the primary sources of data collection concerning tactical-level activities and underlying impacts on DS balancing included semi-structured interviews, direct observations and archival data. The project at SGC allowed for developing an explicit semistructured protocol (Appendix 1).

Previous construction management research claims that several characteristics of the construction industry are unique. Furthermore, the terms used to label activities and processes implemented in other industries and related key competences are different (e.g. Dubois and Gadde 2002). Hence, the protocol in its generic form must be inclusive. Therefore, the protocol was first discussed with three construction management researchers and adjusted over time to ensure the relevance and comprehensiveness of the formulated questions in relation to the intended process activities. An example of such adjustments is the use of 'bid preparation process' as a term instead of order fulfilment process. Further, clarifications were made to some questions (e.g. questions 2.4, 3.3, and 4.2).

The intent of each interview was to map the information flows within the order fulfilment process, the work content of activities, the underlying reasons for each activity, and the tools and systems used to perform the activities. The interviews were conducted to understand and describe how different drivers of complexity come into play and influence the tactical-level planning activities and decisions.

\subsection{Informant selection and data collection}

The regular meetings conducted within the order fulfilment process at SGC involved representatives from research and development (R\&D), marketing and sales, procurement and production, and project management. Accordingly, the interviews involved eight decision makers, as shown in Table 3. In total, eleven 120-min semi-structured interviews were conducted.

According to Flick (2009), observing participants helps to describe social situations, while observing systems assists in understanding the underlying structures of a phenomenon. As described earlier, the authors participated in a project at the SGC over two years. Direct observations were opportunistic during weekly, monthly and quarterly project meetings, focussing on the interaction among participants. The interview protocol and answers from concurrent interviews guided observations. The project meetings progressively addressed all potential tactical-level planning activities and decisions within the order fulfilment process to identify related information system support requirements. Many incoming and ongoing customer orders with actual (confidential) figures and resource information were used during the meetings.

The project also included four semi-annual workshops involving representatives from $R \& D$, sales, engineering, procurement, production and project management in addition to representatives from the internal IT support function and external software providers. The earlier workshops consisted of brainstorming sessions to reach consensus concerning key tactical-level activities and decisions, and to identify respective information system needs. The later workshops consisted of demo and assessment sessions concerning proposed process adjustments and upgrades of existing information system support. The project meetings and workshops allowed for capturing how key actors discuss options and make decisions beyond just documenting their own reflections.

Data collection also included supplementary archival data including official and internal documents. Official documents describe the company background (e.g. history, strategy and mission), competencies and solutions (e.g. types, features, technical data and applications), and news and press releases (e.g. annual reports, recent business initiatives, new flagship projects, and recent technologies). Internal (digital and paper) documents described written communications among the project participants and order fulfilment process maps and related procedures, instructions, templates, worksheets, presentation slides and information systems (e.g. customer relationship management system, resource planning and optimisation systems, project portfolio and project management systems, and virtual design and construction systems). Additional documents from Swedish construction associations were used to gather more insights into the common organisational structures, routines and roles and responsibilities of engineering and production competences. Direct observations and archival data were used to further clarify and validate the main results of the semistructured interviews. 
Table 3. Profiles of interviewees.

\begin{tabular}{|c|c|c|}
\hline Interviewee* & Department & Key role within the order fulfilment process \\
\hline Market analysis manager $^{a}$ & Marketing & $\begin{array}{l}\text { Analyses geographies, sales performance, competition, and core } \\
\text { and adjacent competences }\end{array}$ \\
\hline Head of partnering ${ }^{a}$ & Sales & Directs bidding for partnering projects \\
\hline Head of sales specialists ${ }^{a}$ & Sales & $\begin{array}{l}\text { Directs bidding, assigns key account managers and selects and } \\
\text { prioritises tender requests }\end{array}$ \\
\hline Design leader ${ }^{b}$ & Design & $\begin{array}{l}\text { Directs architects and designers during bidding and pre- } \\
\text { construction design }\end{array}$ \\
\hline Head of research and development ${ }^{b}$ & Research and development & $\begin{array}{l}\text { Directs tender request selection, research activities and } \\
\text { deployment of advanced construction methods and processes }\end{array}$ \\
\hline Production manager ${ }^{b}$ & Production & $\begin{array}{l}\text { Validates specifications of tender requests against production } \\
\text { feasibility and economics }\end{array}$ \\
\hline Production development manager ${ }^{\mathrm{b}}$ & Production & $\begin{array}{l}\text { Aligns tender requests with production capabilities, and reviews } \\
\text { designs and delivery plans }\end{array}$ \\
\hline Resource planner ${ }^{\mathrm{b}}$ & Production & Assigns bidding teams \\
\hline Project Manager ${ }^{b}$ & Project management & $\begin{array}{l}\text { Coordinates bidding and supports production and } \\
\text { procurement functions }\end{array}$ \\
\hline Human resource manager ${ }^{b}$ & Human resources & $\begin{array}{l}\text { Provides regular feedback on external and internal competence } \\
\text { criticality and rareness and possibilities of substitutability } \\
\text { between positions and individuals }\end{array}$ \\
\hline
\end{tabular}

*Functional orientation: ${ }^{\mathrm{a} D e m a n d}$ or ${ }^{\mathrm{b}}$ Supply

\subsection{Data analysis}

Data analysis followed specific procedures to ensure reliability and validity. The authors compiled field notes, reflections and perceptions to summarise and corroborate the primary case-study narrative. When discrepancies appeared, the authors referred to the interviewees. Two key interviewees reviewed the detailed case description. This enabled higher accuracy in the narrative.

The authors adopted content analysis by first dividing customer orders into five categories (research-, develop-, design-, modify- and combine-to-order) using Table 1 as a guiding framework (i.e., based on the number and type of engineering activities needed to process customer requests after the entry of these requests). These categories served as embedded single cases. Examples of historical orders that represent internal product families and match the characteristics of each order decoupling categories, as described in Table 1, were suggested by some key interviewees.

To initially validate that the matched orders belong to the corresponding decoupling categories, variations of order fulfilment activities within and across the categories were analysed. Then, the authors needed additional information about characteristics associated with the product families of the matched orders to compare and check if the orders grouped together reflect sufficient commonality and homogeneity from a planning perspective. In line with Gosling, Hewlett, and Naim (2017), the study incorporated typical customers, inputs from customers, and final products. Types of customer requests and contractual conditions, potential risks and margins and project durations were also incorporated. This is because they introduce additional constraints and characterise the typology of ETO organisations and activities (Hicks, McGovern, and Earl 2001). Finally, the authors identified examples of generic critical competences associated with each order category due to critical competences being relevant to tactical planning in ETO SCs (Cooper and Budd 2007).
Relating orders to decoupling categories allowed for extending the generalisability of the results within ETO SCs. It also enabled identifying how the order fulfilment process activities and decisions may respond to various levels of structural and dynamic complexity generated by various customer orders. This required mapping the activities, decisions and related information flows, departing from the generic conceptual framework of tactical planning (Figure 1). Differences showing how the activities and decisions vary when processing various orders that belong to various decoupling categories were identified and discussed with the related interviewees to further understand the underlying reasons. The differences in the tactical-level activities and decisions associated with various orders served as evidence for how SGC reduces or absorbs the complexity constraining DS balancing.

To ensure relevance to tactical plannning, the data about the identified activities had to provide evidence for a potential impact on fulfiling the company's medium-term objectives disaggregated from the overall long-term business objectives. These medium-term objectives were referred to as strategic alignment (e.g. Kristensen and Jonsson 2018). To capture relevant key tactical-level decisions, the authors identified events that required selecting one among several feasible options applicable in the medium term.

The second part of analysis addresses the tactical-level decision impact on the complexity constraining DS balancing. As described in Section 2.3, this study synthesised insights from two relevant works to establish categories of complexity drivers (Table 2). This guided coding by sorting related case data accordingly and facilitated inferring indirect impacts on the complexity constraining DS balancing.

Dynamic complexity and uncertainty are two different concepts as other aspects like plannable, not necessarily uncertain, variations also generate dynamic complexity. Yet, inferring how decisions affect dynamic complexity was included in this study based on the decision impact on uncertainties. This is because dynamic complexity is largely 
induced by uncertainties. Similarly, there are differences between two types of details related to structural complexity: the amount of details that inform a decision (i.e. details generated by a process), and the level of structural complexity of a SC (i.e. details generated by a SC). However, inferring how decisions affect structural complexity was included in this study based on the decision impact on details without relating to a definite type. This is because many possible overlaps between the two types exist. Furthermore, in many cases, the details generated by a process are influenced by the details generated by a SC.

Therefore, to analyse the decision impact on complexity, the related collected data had to provide evidence on how decisions led to increased or reduced details and uncertainties. This is in line with the information-processing logic of Galbraith (1977). Accordingly, data that showed that decisions potentially lead to decreases in the details and uncertainties generated by a driver served as evidence for reducing the complexity constraining DS balancing. In contrast, data that showed that decisions potentially lead to increases in the capacity to process details and uncertainties served as evidence for absorbing the complexity constraining DS balancing.

\section{Analysis}

\subsection{SGC and related decoupling categories of customer orders}

As a general design and construction contractor of residential and industrial facilities and infrastructure, and as a research partner taking part in projects dedicated for innovative built environment (e.g. energy-saving buildings and lowdisturbance production), SGC is one of the major players that dominates the Nordic markets. It is represented by more than 30 offices including a headquarter in Sweden. SGC generates revenue of around $300 \mathrm{k} € /$ employee through delivering projects (customer order) of several types, which fall into five engineering decoupling categories (see Table 4).

In the Swedish construction market, customers publish enquiries for tendering and distribute project briefs through a platform called 'Sverige Bygger'. Customer orders are either requests for price quotation (RFQ), or requests for information (RFI) about production capabilities (more than a price tag) that precede requests for proposal (RFP) with detailed plans.

Order category 1 includes customer enquiries that need engineering research and often entail long-term commitment. Public agencies, the typical customers in this case, set ambitious product specifications for mega projects such as buildings, infrastructural open urban spaces or ambitious production specifications such as construction with minimal disturbance in densely occupied areas and minimising carbon emissions to ambitious levels. Such enquiries normally entail partnering where the agencies select multiple general contractors after tendering to negotiate between each other before signing a cost-plus-fee contract. These contracts offer low margins but ensure more stable income over longer periods. However, the potential risks lie in the substantial uncertainties embedded in the extremely long project periods and the challenging specifications (quality) requested.

Order category 2 includes enquiries that need developing new or integrating established design codes and standards. This is a common need triggered by industrial businesses that, for instance, plan to manufacture or process new types of hazardous material in their facilities which lack corresponding codes or standards. In this case, SGC develops new codes by decoding universal codes, that are typically issued by professional societies and national standard bodies, to derive artefacts to the customer requirements and contexts. Therefore, it integrates new codes into established codes. Otherwise, it redrafts relevant existing codes to obtain public permissions and market acceptance. Like category 1, the potential risk for category 2 is to deliver the results as agreed, considering the long project periods in question. Regarding the quality, the uncertainties concerning the specifications seem to be lesser than the case for category 1 . This is because the relevant test results from related engineering research that support the developments in codes of practice already exist.

Order category 3 includes enquiries that need new designs which are based on existing codes and standards, such as museums. Winning such projects most of the time implies the possibility of signing turnkey lump sum contracts with public agencies or developers to deliver both design and construction results that fulfil a set of desired specifications. Usually, such contractual conditions hold potentials of large profit margins. However, the associated risk stems from the narrower tolerance of delivery deadlines and budgets due to increasing competition in respective segments.

Finally, order categories 4 and 5 include enquiries that need modifying or combining existing designs, respectively. Public agencies or developers, through design or architectural consultants, develop highly specified briefs and design outlines that require either minimal or no unit design prior tendering. Yet, regardless of the requirements, SGC needs to develop designs and plans concerning the construction phase. The tender requests here are often based on unitprice contracts. Due to the fierce competition in the respective segments, the associated risk stems from the compressed budgets that demand high production efficiency. For category 5 , an additional risk related to quality may apply due to the limited design flexibility granted to SGC. This, as the case for category 4, constrains possibilities to resolve potential incompatibilities between product designs and feasible construction designs that, in turn, ensure smoother production.

\subsection{Order fulfilment at SGC}

SGC uses a customer relationship management software to track all customers enquiries published at Sverige Bygger, which initiates order fulfilment activities. Subsections 4.1-4.5 describe these activities departing from the generic subprocesses of the conceptual framework presented in Figure 1. 
Table 4. Characteristics of order categories at SGC.

\begin{tabular}{|c|c|c|c|c|c|}
\hline Category & Order category 1 & Order category 2 & Order category 3 & Order category 4 & Order category 5 \\
\hline $2 D-C O D$ & $\begin{array}{l}\text { Engineering research } \\
\text { Purchase material }\end{array}$ & $\begin{array}{c}\text { Develop or integrate } \\
\text { codes or standards } \\
\text { Purchase material }\end{array}$ & $\begin{array}{l}\text { Design } \\
\quad \text { Purchase material }\end{array}$ & $\begin{array}{l}\text { Modify design } \\
\text { Finalise production }\end{array}$ & $\begin{array}{l}\text { Combine: Finalised } \\
\text { module designs } \\
\text { Finalise production }\end{array}$ \\
\hline Typical customers & Public agencies & $\begin{array}{l}\text { Public agencies, } \\
\text { industry businesses }\end{array}$ & $\begin{array}{l}\text { Public } \\
\quad \text { agencies, developers }\end{array}$ & $\begin{array}{l}\text { Public } \\
\text { agencies, developers }\end{array}$ & Developers \\
\hline $\begin{array}{l}\text { Typical input } \\
\text { from customers }\end{array}$ & $\begin{array}{l}\text { Constraint specification } \\
\text { and approvals }\end{array}$ & $\begin{array}{l}\text { Tendering } \\
\text { documentation and } \\
\text { negotiation }\end{array}$ & $\begin{array}{l}\text { Tendering } \\
\text { documentation and } \\
\text { negotiation }\end{array}$ & $\begin{array}{l}\text { Requirements and } \\
\text { technical approvals }\end{array}$ & $\begin{array}{l}\text { Order with project } \\
\text { documentation }\end{array}$ \\
\hline $\begin{array}{l}\text { Examples of } \\
\text { building units }\end{array}$ & $\begin{array}{l}\text { Innovative energy } \\
\text { saving buildings }\end{array}$ & $\begin{array}{l}\text { Laboratory and } \\
\text { chemical facilities }\end{array}$ & Museums, sport facilities & Halls of residence & Halls of residence \\
\hline Typical requests & $\mathrm{RFI}^{\mathrm{a}}$ then $\mathrm{RFP}^{\mathrm{b}}$ & RFI then RFP & RFI then RFP & $\mathrm{RFQ}^{\mathrm{c}}$ & RFQ \\
\hline Typical contracts & Cost-plus partnering & Cost-plus partnering & Lump-sum $D^{d}$ & Unit-price $\mathrm{DBB}^{\mathrm{e}}$ & Unit-price DBB \\
\hline Potential risks & Quality, time & Time & Time, cost & Cost & Cost, quality \\
\hline Potential margins & Low & Low & High & Medium & Low \\
\hline Avg. duration & 10 years & 5 years & 2 years & 1 years & Months \\
\hline $\begin{array}{l}\text { Internal generic critical } \\
\text { competences } \\
\text { (examples) }\end{array}$ & $\begin{array}{l}\text { As same as the case for } \\
\text { order category } 2+ \\
\text { field-specific } \\
\text { research engineers }\end{array}$ & $\begin{array}{l}\text { As same as the case for } \\
\text { order category } 3+ \\
\text { partnering sales } \\
\text { specialists }\end{array}$ & $\begin{array}{l}\text { As same as the case for } \\
\text { order category } 4+ \\
\text { design leader }\end{array}$ & $\begin{array}{c}\text { As same as the case for } \\
\text { order category } 5\end{array}$ & $\begin{array}{l}\text { Senior project and site } \\
\text { managers, } \\
\text { construction } \\
\text { engineers, estimator, } \\
\text { surveyors, buyer, } \\
\text { installing and } \\
\text { measuring technician }\end{array}$ \\
\hline$\%$ of total sales & $\% 5$ & $\% 40$ & $\% 40$ & $\% 10$ & $\% 5$ \\
\hline
\end{tabular}

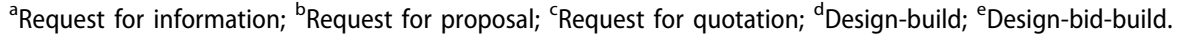

\subsubsection{Preliminary assessment of customer enquiries}

The head of sales specialists goes through each new tender request and assigns a relevant key account manager. Sales specialists gather data and assess factors like the completeness of the specifications, customers' behaviour towards change requests and win-rates. Every week, the manager of sales specialists holds a meeting during which representatives from sales and marketing, R\&D, design, procurement, production and project management review assessments and make decisions concerning incoming and ongoing enquiries as well as projects at design and construction stages. Departing from corporate objectives, sales and marketing representatives provide information about future markets in certain geographies and segments, current and expected sales performance, competition in each segment, benchmarks and future trends and pressures on core and adjacent competences.

Procurement, production, and project management are typically more influential when selecting and prioritising enquires that demand critical competences during tendering, pre-construction design and construction phases. These are often enquiries that correspond to categories 1-3 (see internal generic critical competences on Table 4). For SGC, critical competences represent rare skills and expertise which are usually developed internally by individuals who are normally extremely difficult to acquire on short notice. Therefore, when referring to DS balancing, SGC means matching available enquiries with critical capacity. The resource planner also indicates that 'the critical labour productivity can dramatically increase if they are allocated to projects that allow them to utilise their skills sets and expertise. For instance, junior project managers are either not able or very slow to deliver results for large-budgeted projects as compared to senior project managers'. In this respect, procurement provides information about supplier options and reliabilities to answer questions like if a certain project requires minimal internal capacity to ensure greater flexibility to the capacity planning of more prioritised projects.

The inputs of R\&D are crucial for assessing enquiries representing order categories 1 and 2 due to greater uncertainty concerning the engineering feasibility of the solutions requested. Furthermore, R\&D provides practical information such as the deployment of advanced construction methods and processes in different segments, which may influence selecting and prioritising enquiries representing categories 3-5.

One part of the weekly meeting outcomes represents selected and prioritised (ranked) enquiries for further analysis, excluded undesirable enquiries, and allocated specialists to conduct the analysis. Excluding enquiries can potentially occur at any stage if SGC has not yet signed the corresponding contracts.

\subsubsection{RCCP and procurement related to tender- ing activities}

According to the production development manager, 'any tendering analysis requires at least a project manager, an estimator, a design leader, a buyer, a site manager or a construction engineer, a surveyor, and an installing and measuring technician. Specific seniority and certification requirements on each position may apply'. The production development manager and the project manager agree that these teams are autonomous in nature concerning how they deliver results. However, they still emphasise that all teams usually follow a logical sequence. This is in line with the order fulfilment process guidelines. Normally, estimators start working with design leaders to define the need for external and internal design and planning specialists, and buyers come into play to support such decisions. The amount of design work depends on the type of bidding and contracting conditions, i.e. design-bid-build (DBB) or design-build (DB). However, the production manager indicates that, 'to validate 
design fulfilment, [SGC] tends to always review the design needs even if designs are provided externally'.

Specialists possessing critical competences are subject to organisational reshuffling during their ongoing assignments. The resource planner explains: 'Our strategy to satisfy the individuals with critical competences by matching them with the most suitable projects and positions paid off, and we continue to strictly follow this strategy through paying attention to the dynamics of the market and our competences'. If Sverige Bygger notifies SGC of incoming partnering flagship projects, which correspond to categories 1 and 2, and managers fail to secure key positions, like suitable sales specialists and project and site managers, SGC 'does not think twice to consider reassigning of individuals over ongoing projects to unlock the suitable candidates that live up to the challenge'. Individuals also grow and become notable, showing evidence for greater maturity, delivering reliable results, and collecting qualifications and certifications. The resource planner says: 'Our discussions during the weekly meetings may lead to promoting notable individuals in consultation with HR'. This entails replacing them with other promoted individuals from lower levels. Consequently, reshuffling of many other individuals over ongoing projects may be necessary to relieve additional workload off the critical specialists' shoulders, creating room for filling more challenging gaps.

\subsubsection{Macro process planning}

The tendering analysis teams develop unit design solutions that fulfil specifications stated in the respective project briefs. Such process becomes longer and more cross-functional moving from order category 5 towards 1 as the level of detail in the respective customer input decreases (see typical input from customers in Table 5). For instance, R\&D needs to participate in such analysis only if incoming enquiries belong to categories 1 and 2 to identify the specific design areas that need engineering research and code development, integration, or redrafting. Once the design specialists of the analysis teams develop satisfactory design solutions, the production specialists cooperate with each other to discuss whether the design specifications have issues that can complicate production, select appropriate manufacturing processes, and define the specifications of temporary work (e.g. scaffolding).

\subsubsection{RCCP and procurement related to produc- tion activities}

After the designs are developed, and the manufacturing processes selected, the resource planner, the production manager, the buyer, and the project and site managers cooperate with each other to determine the capacity, materials, logistics and technology needed from external contributors, and the ways of obtaining price and delivery time quotations or proposals. The estimator combines the estimates concerned with internal and external capacity into a 'method statement' leading to the estimate of total cost and delivery date.
Projects in categories 1 and 2 tie-up individuals with critical competences for extended periods, which is disadvantageous from a flexibility perspective. Some positions like sales specialists and buyers are needed during certain project periods not necessarily in full capacity, which provides short- to medium-term availability. Other positions like project managers are responsible for several parallel projects, but they stay so from the beginning until the end of the projects, while positions like site managers require full dedication to a single project during the construction phase.

As described earlier, SGC considers promoting and substituting individuals when needed. However, substituting key individuals across projects is not that simple as the new replacing individuals must properly familiarise themselves with all vital details concerning the project status and issues. Moreover, some customers may select SGC just because certain famous site managers, for instance, are assigned to the construction phase of their projects. Drawing such individuals in the middle of project execution will more likely result in additional difficulties.

\subsubsection{Order acceptance: final review and potential negotiation}

During the weekly meeting mentioned earlier, enquiries that received proper analysis and have estimations of total costs and delivery dates are reviewed once again considering the revealed data. Enquiry reviews serve as capacity re-planning points. SGC changes the plans developed during tendering activities, either directly through change requests, or indirectly through reducing the priority of or excluding enquiries due to revealed undesirable results. According to the head of sales specialists, 'in rare cases, [SGC] may reject tender requests even just before contracting'. In short, SGC updates the aggregate (tactical) plans on a weekly basis. It also treats incoming enquiries as disturbances that need certain re-planning rules.

Marketing determines profit margins and assesses the price effect on the win-rate, where changes concerning outsourcing and resource allocation (reshuffling of resources) may be suggested to optimise the overall critical resource utilisation. The meeting concludes with approved enquires that proceed with documentation and submission.

When customers select SGC, negotiating the contract terms starts. Sales specialists may negotiate increased compensations for additional suggested features or replacements of certain individuals with critical competences to provide greater flexibility to resource planners. However, clients may still select contractors because of these individuals.

In case of partnering projects related to categories 1 and 2 , negotiations are more challenging than the case for categories 3-5 and require trained sales specialists with critical skills. The head of partnering claimed that 'contracting can be costly and much more time consuming when clients invite multiple general contractors to cooperate and co-produce units as reaching consensus is imperative'. 
Table 5. Decision impact on SC complexity drivers at SGC.

\section{Key decisions \\ TD1: Select and prioritise enquiries}

TD2: Assign capacity to enquiry analysis

TD3: Determine external capacity

TD4: Design geometrics and select material

TD5: Select mfg. processes and equipment

TD6: Pre. allocation of internal capacity

TD7: Select external contributors-execution

TD8: Determine changes-design/execution

TD9: Accept or reject enquiries
Case data excerpts describing the decision impact on complexity drivers ${ }^{\mathrm{a}, \mathrm{b}}$ at $\mathrm{SGC}$

Related drivers: DC1, DC2, DC3, DC4, DC5, SC1, SC3, SC4, SC5, SC7, SC8, SC10

Head of sales specialists: '[TD1] can dramatically increase the number of customers [DC1] and [SGC] prefers to focus on less customers that are reliable, generate most of the company's total sales, and really know what they need [DC4 and 5]. Less customers imply less potentially late change requests, thus, less reworks or delays, which requires extra capacity and, thus, disturbs the overall schedule'. ' ... the coordination with large-sized customers is more demanding'. Head of partnering: 'Each partnering project [from category 1 and 2] is at its foundational problem unique and based on immature technologies [SC3] ... [SGC] has many of such projects' The production development manager: 'The advantage of having module-based projects [SC5] [from category 4 and 5] with minimum unique building units [SC1] is the generally less required engineering work related to the products [SC4] and production [SC8] as briefs are very explicit [DC4] and there is very limited room for improvisation [SC7].' Head of R\&D: 'R\&D never participates in [order fulfilment] if codes and standards should satisfy the enquiry in question [SC10].'

Related drivers: DC1, DC2, DC3, DC4, DC5, SC3, SC4, SC5, SC7, SC10, SC11

Resource planner: 'The inaccessibility to individuals holding critical competences, such as highly certified project managers, means no-go for some large customers [DC1 and 2] as these are capable of handling projects requiring substantial uniqueness [SC4] and expertise in many fields [DC3]'. Head of partnering: 'The sales specialists involved in partnering projects need at least 3year training to be able to deal with the respective customers that are usually uncertain about what they want [DC4]'. Design leader: 'Involving engineers with direct prior experience with customers that have negative records in late change requests is a big plus to better understand their briefs [DC5]. Sometimes, engineers are responsible for reducing costs by considering module-based buildings [SC5], which is encouraged at [SGC] under competitive bidding on turnkey projects [category 3]' Head of R\&D: 'Dealing with immature technologies [in partnering project, i.e. category 1 and 2] requires research engineers capable of embracing uncertainty'. Project manager: 'In partnering projects [category 1 and 2], we have more flexibility as [enquiry analysis] teams need to suggest solutions to customers and select the concepts that best meet their needs [SC7]'. ' ... we need to involve more departments [SC10] than in regular projects [categories 3-5]'. Production manager: 'The [enquiry analysis teams] should consider the capabilities and risks associated with available subcontractors [SC11]'.

Related drivers: SC6, SC7, SC10, SC12

Resource planner: '[SGC] recommends relying on less external parties under tendering [SC6] to minimise the risk of losing confidentiality. However, we still need a great deal of external consultants [SC10] to keep up with the influx of enquiries'. ' ... they are normally preferred in less prioritised projects that need minimal engineering [category 3-5]' Production development manager: 'We know that centralised procurement is better, but we want to satisfy project and site managers who claim that the freedom to select subcontractors is a project success factor [SC7], which is why [SGC] manages an enormous supply base [SC10 and 12]'

Related drivers: SC2, SC3, SC4, SC5, SC8, SC9

Production development manager: 'The housing industry [category 4 and 5] is highly restricted by design codes, which often narrows down the options left for designers and planners [SC4]'. ' ... in industrial facilities [category 4], designers and planners either simplify buildings by increasing the number of modules [SC5] or complicate them by geometrics and material [SC2] that are challenging to manufacture and build [SC3, 8 and 9].' ' ... having highly detailed geometrics [SC2] with materials we are unfamiliar with [SC3] increases the probability of disturbances like reworks and delays during execution'.

Related drivers: SC3, SC8, SC9

Production development manager: 'We depart from a technology readiness scale when determining tooling options [SC3]'. ' ... in partnering projects [category 1 and 2], we may consider low maturity levels to show our capabilities to the customers, but we stick to highly mature production options in regular segments to be able to compete on price by minimising potential risks for disturbances [SC9]'. ' ... process engineering under mature production options is about selecting well tested equipment and methods like 3D printing, which enables producing complex unique shapes much faster and at minimal risks [SC8]'.

Related drivers: SC6, SC9, SC10

Project manager: 'Selecting internal project team members also depends on the type and quantity of subcontractors and other suppliers'. ' ... you need more experienced site managers and foremen when you have no option but to deal with poor-performing subcontractors [SC9] or when you have too many suppliers in general [SC6 and 10]'.

Related drivers: Same as the impact of TD3 on SC6, SC7, SC10, SC12 and impact on SC9, SC11

Project manager: 'We need to freely select subcontractors for our projects to minimise the overall risks. Centralised procurement does not allow this when, for example, projects are located far from the possible supply options.' Production manager: ' ... projects whereby the involvement of external contributors is highly intertwined with internal activities, are more sensitive to delays and reworks [SC9] than projects in which such involvement is more separated and parallelised.' Head of sales specialists: 'The share of external parties per project should ensure minimum overall risks across all projects.'

Related drivers: SC2, SC3, SC6, SC9, SC10, SC11, SC12

Head of sales specialists: 'We review all the assumptions and solutions that the [enquiry analysis] teams propose for the ongoing enquiries to decide if we should respond with tenders'. ' ... compromises and changes across enquiries are usually made on procurement [SC6 and 10-12], design [SC2], and production options [SC3 and 9] to maximise the total sales'. 
Design leader: 'The tendency of some sales specialists at [SGC] who purposefully encourage and approve enquires with design uniqueness, even if it is unnecessary, as to distinguish ourselves as a contractor led to a proliferation of various design details [SC2] that fulfil the same functional and spatial requirements'.

'Demand-related drivers include DC1: Number of customers, DC2: Size of customers, DC3: Heterogeneity in customer needs, DC4: Customer's product knowledge, and DC5: Customer's order change behaviour

${ }^{\mathrm{b}}$ Supply-related drivers include SC1: Number of products, SC2: Number of components, SC3: Technology maturity, SC4: Breadth of customisable product structure, SC5: Degree of design modularity, SC6: Number of external contributors, SC7: Sales and engineering process structures, SC8: One-of-a-kind or low volume batch production, SC9: Manufacturing schedule instability, SC10: Cross-functional interfaces, SC11: Reliability and length of supplier lead times, and SC12: Supply base globalisation

Engineering process sub-flows

\begin{tabular}{|c|c|c|c|c|}
\hline Research & $\begin{array}{c}\text { Category } \\
1\end{array}$ & & & \\
\hline Develop & $\begin{array}{c}\text { Category } \\
2\end{array}$ & & & \\
\hline Design & $\begin{array}{c}\text { Category } \\
3\end{array}$ & & & \\
\hline Modify (major changes) & & $\begin{array}{c}\text { Category } \\
4\end{array}$ & & \\
\hline Modify (minor changes) & & $\begin{array}{c}\text { Category } \\
4\end{array}$ & & \\
\hline Combine & & $\begin{array}{c}\text { Category } \\
5\end{array}$ & & \\
\hline
\end{tabular}

Figure 2. Generalisability of results across 2D-COD points, adapted from Cannas et al. (2019).

\subsection{Impact of key tactical-level decisions on complexity constraining DS balancing}

Managers at SGC make nine key tactical-level decisions (TDs) within the order fulfilment process before the pre-construction design phase: selecting and prioritising enquiries (TD1), assigning capacity to enquiry analysis (TD2), determining external capacity (TD3), selecting design and material options (TD4), selecting manufacturing options (TD5), preliminary allocation of internal capacity (TD6), selecting external contributors (TD7), selecting final options (TD8) and accepting or rejecting enquiries (TD9).

These decisions have potential impact on the details and uncertainties constraining DS balancing. They may push the actual capacity level away from the DS balance state towards over- or under-capacity states. Table 5 describes the impact of each decision on related complexity drivers, including relevant interview quotations. The quotations include codes defined at the bottom of the table that refer to the drivers. The codes are placed after phrases that support their relationships with respective decisions. DC1 to DC5 refer to demand-related complexity drivers. $\mathrm{SC} 1$ to $\mathrm{SC} 12$ refer to supply-related drivers. Table 2 in Subsection 2.3 presents how these drivers change to increase or reduce details and uncertainties.

The results show that TD1, TD2 and TD9 have significant impact on the details and uncertainties constraining DS balancing as these decisions are associated with both demandand supply-related complexity drivers, unlike TD3-TD8 that have more direct impact on supply-related drivers.
TD1 and TD9 may entail increases in the number of customers and potential consequent schedule disturbance reflected from late change requests, reworks, and delays, thereby calling for additional capacity to meet the originally contracted specifications. TD1 and TD9 influence the percentages representing the number of projects corresponding to each order category. Increasing the percentages of categories 1 and 2 implies dealing with more immature technologies. On the contrary, increasing the percentages of categories 4 and 5 implies dealing with less overall design uniqueness across projects, less product and production engineering work and fewer participating functions (e.g. R\&D). TD1 and TD9 represent the same decision in two phases. TD9 occurs after the analyses of incoming enquiries end, which means that TD9 does not affect the capacity needed for conducting the analyses. TD1 precedes product design analyses, which means that TD1 does not affect any consequent results like the amounts of design detail. Meanwhile, TD9 may purposefully lead to increases in the overall amounts of design detail across projects.

TD2 may entail reductions in the information-processing capacity required to meet the intake of certain enquiries, especially the ones corresponding to order categories 1 and 2 where customers are usually large-sized, more unexpected (in terms of late change requests) and uncertain about their needs, and where the high overall level of inter-project uniqueness requires high levels of specialised expertise and implies dealing with immature technology. Therefore, assigning critical competences to enquiries corresponding to order categories 4 and 5 represents a form of underutilisation to such competences. TD1 and TD2 are to a great extent mutually related. SGC selects enquiries to unlock as many constraints as possible on individuals with critical competences. Thus, together, TD1 and TD2 significantly shape the complexity constraining DS balancing.

\section{Discussion}

\subsection{Tactical-level planning activities and decisions in an ETO environment}

To increase generalisability of findings associated with single cases, this study addressed how a first-level single case (an order fulfilment process) manages five second-level single cases (order decoupling categories). Figure 2 shows six decoupling configurations of the 2D-COD matrix introduced 


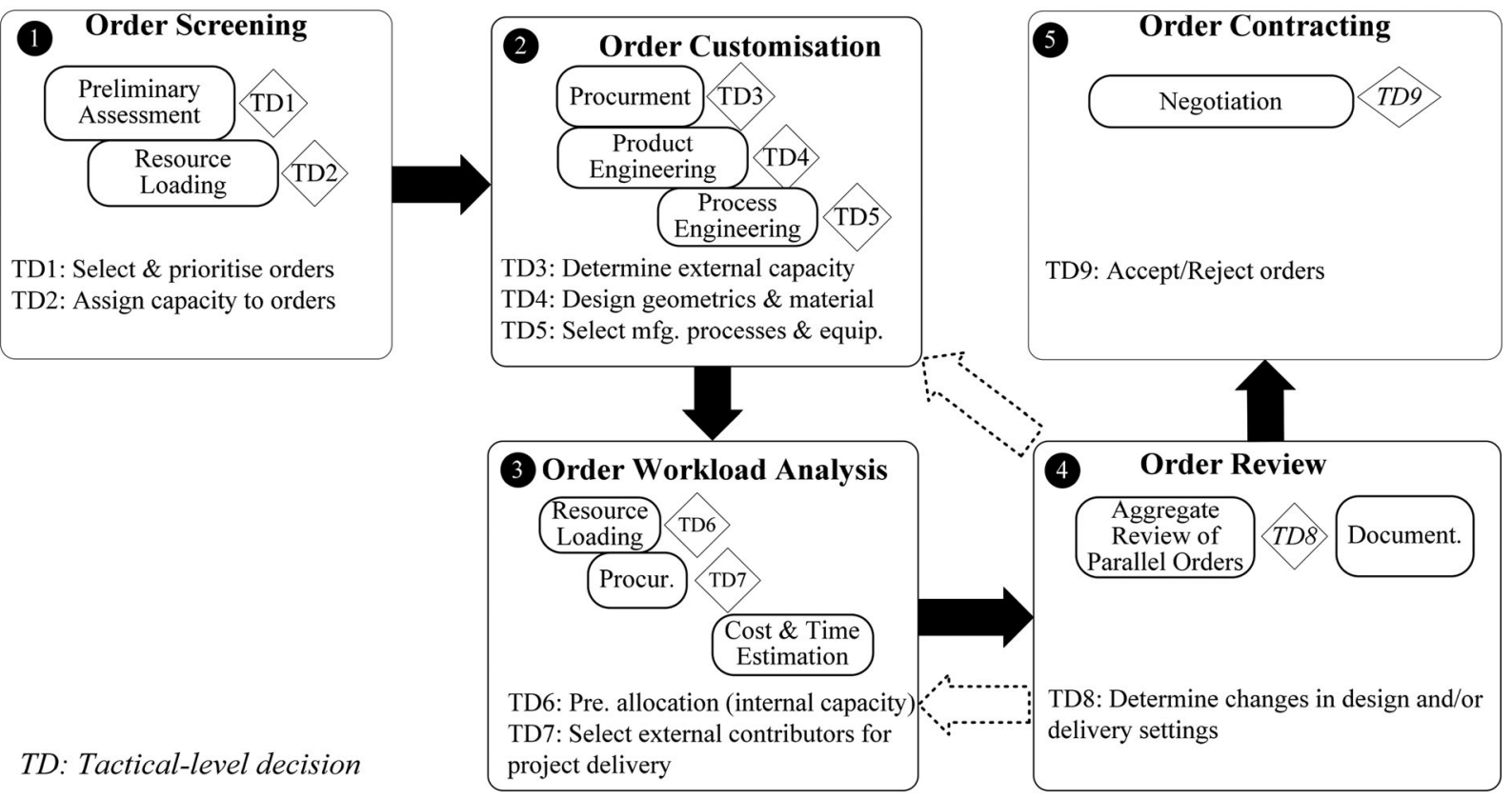

Figure 3. Tactical-level planning activities and decisions in ETO settings.

by Cannas et al. (2019) (denoted in grey-shaded squares). These configurations match the five COD categories which were conceptually identified (Table 1) empirically analysed (Table 4). The findings are, consequently, directly relevant to these configurations.

Findings show that organising planning processes in a cross-functionally integrated structure enables tactical planning to comprehensively and timely identify DS balancing issues. This is also the case for other tactical-level planning processes like S\&OP (Kristensen and Jonsson 2018). Thus, instead of presenting tactical-level planning sub-processes as groups of different planning areas, as suggested in literature, findings detail the underlying sequential cross-functional activities. A proper sequence of planning activities is important for minimising unnecessary communication and maximising decision-making support (Oliva and Watson 2011).

Hans et al. (2007) presented RCCP and enquiry selection as a unified sub-process. However, they did not explicitly show if enquiry selection and acceptance are two distinct sub-processes. Accordingly, findings show that the order acceptance sub-process encompasses preliminary assessment, aggregate review of parallel orders, negotiation, and a series of successive decisions that entail accepting or rejecting enquiries. Therefore, rejecting orders in the late process stages (even after winning contracts) is possible, which has not been explicitly clarified in extant research, probably because of penalties imposed by clients in other ETO SCs.

Findings show that the sub-process of RCCP has two main resource loading activities; before and during enquiry analysis, and an activity to determine the overall costs and the earliest delivery dates. The latter is important to optimise the overall return on internal capacity across enquiries. Giebels (2000) and Carvalho, Oliveira, and Scavarda (2015) argued that resource loading starts after order acceptance regarding post-contract engineering. Findings show that the engineering activities before contracting are also important due to frequent needs to assess engineering requirements of incoming enquiries (Olhager 2010) and the scarcity of the competences typically involved (Cooper and Budd 2007).

Finally, findings show that procurement occurs in two occasions: before completing product design analysis, and in parallel with the resource loading for project execution. This is also not explicit in related research.

Following the process structure of Day (1994), Figure 3 presents the proposed tactical-level activities and decisions in sequence drawing on the order fulfilment process description of the case. The squares numbered 1 to 5 represent the sub-processes. The rectangles inside the squares represent the tactical-level activities, while the diamonds numbered from TD1 to TD9 represent the tactical-level decisions. The solid arrows represent the sequence of the sub-processes, while the dotted arrows represent potential detours back to previous sub-processes depending on the decisions made within the sub-process of order review.

In order screening, several functions at multiple hierarchical levels interact with each other to assess demand and prioritise the most strategically fit and tactically feasible customer orders. Preliminary assessments entail resource loading decisions concerning the engineering capacity dedicated to order customisations and workload analyses. More customer orders corresponding to research- and develop-toorder configurations (i.e. order categories 1 and 2), considerably increase the number of activities within order customisations and workload analyses. Combine-to-order customer orders (i.e. order category 5) require minimal engineering activities. After resource loading, solutions concerning design geometrics, material selection, manufacturing processes and equipment, and logistics are developed, followed by related make-or-buy decisions. 
Product engineering aims at developing competitive solutions, while process engineering aims at validating manufacturing feasibility. Together, both processes serve as order customisation that ends with deciding the product- and process-related designs to proceed with.

After developing and selecting designs, plans and materials, the corresponding workload is analysed to develop a rough-cut capacity plan at an aggregate level. This starts by preliminary project resource loading of internal capacity. Subsequently, external contributors are approached through tendering or direct RFQ to estimate costs and durations, and to identify constraints, risks and requirements. Research- and develop-to-order customer orders demand internal capacity. Meanwhile, modify- and combine-to-order customer orders may accept more external intervention. Eventually, all estimates are merged together into sequenced activity plans with total costs and the earliest delivery dates for the parallel customer orders.

The top management reviews these findings at an aggregate multi-project level with emphasis on commercial aspects such as competitiveness and financial risks. Changes in details, such as product designs, production processes and external contributions can be suggested for one or more customer orders to optimise the overall competitiveness, growth, and profitability. Therefore, pricing is iteratively conducted, and profit margins are finally determined. This review may sacrifice, or more highly prioritise, some ongoing orders before the documentation of all the approved orders is transmitted to the corresponding customers. After contracts are awarded, terms are negotiated concerning delivery dates and capacity, and detail project planning and scheduling are triggered once the contracts are signed. Contracting seems to need longer periods and more critical competences in case of research- and develop-to-order customer orders.

\subsection{Managing complexity for DS balancing through tactical-level decision making}

Drawing on the findings described in Table 5, nine tacticallevel decisions have potential (reducing or absorbing) impacts on the complexity constraining DS balancing. Out of these decisions, four seem to mediate the effect of the rest of the decisions on complexity including selecting customer orders (TD1), allocating internal capacity (TD2), selecting external contributors (TD7) and determining changes upon order review (TD8). These decisions are embedded in three main DS balancing activities: 1 . Order selection and prioritisation, 2. Supplier selection, and 3. Multiple-project optimisation. The potential impacts of the decisions on complexity seem to increase when ETO companies prioritise requests corresponding research- and develop-to-order configurations.

Figure 4 shows that reducing and absorbing demandand supply-related complexity is possible through the activities of order selection and prioritisation, and supplier selection. Furthermore, DS balancing, given a certain setting of ETO SC complexity, is possible through multi-project optimisation. The next three sections discuss the foundations of these findings.

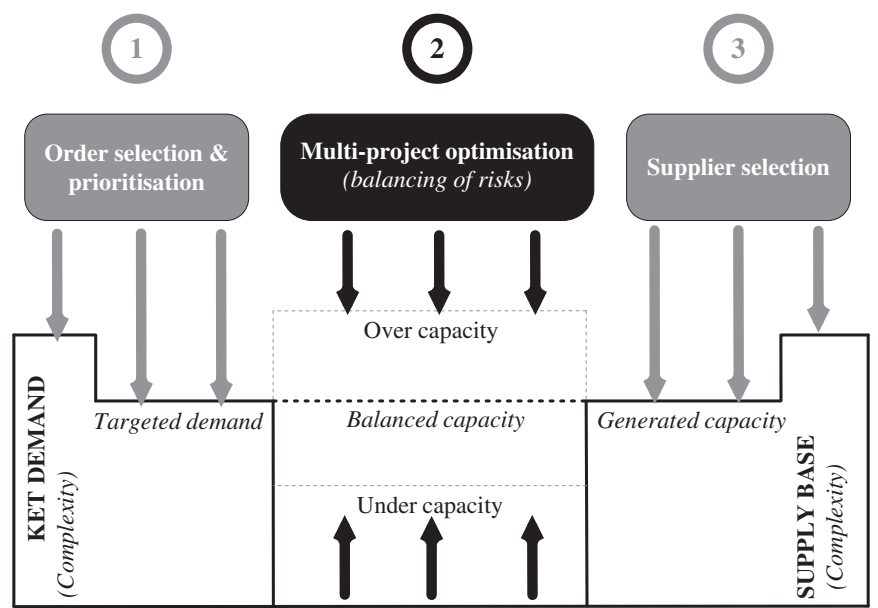

Figure 4. Balancing demand and supply through managing complexity.

5.2.1. Reducing and absorbing SC complexity constraining DS balancing through decisions related to customer demand. In ETO environments, tying resources to customer orders typically entails dedicating these resources to individual projects over extended periods. That is, certain types of resources become more essential than others due to their rareness and uniqueness. Findings show that selecting, prioritising (TD1), and eventually winning orders that require engineering research or developing new codes and standards after order entry (order categories 1 and 2) entail tying individuals who possess scarce competences (TD2 and TD6) to manage the underlying complexity of such orders. Managing research- and develop-to-order demand needs exceptional coordination competences to absorb the substantial structural and dynamic complexity stemming from the required interaction intensity. Orders with corresponding configurations call for dealing with the following: (1) largesized organisations and functions, (2) underdeveloped problem statements and specifications combined with higher degrees of freedom to propose and develop solutions to customers, (3) frequent change requests, (4) low levels of technology readiness and (5) broad customisable product structures that impede modularisation (Cannas et al. 2020).

Fernández Campos, Trucco, and Huaccho Huatuco (2019, $618)$, concerning complexity reduction practices, state that 'variety reducing practices mitigate the negative impact of product portfolio'. That is, focussing on fewer reliable, rather than many random, customers that demand more common and less varied product functionalities and features minimises the detail and dynamic complexity ETO SCs must manage. ETO companies target core segments through dedicating and continuously improving their capabilities to meet the needs of core customers within reduced domains. This is consistent with Cooper and Budd (2007) who claimed that demand validation means aligning order selection with the company's critical capability to perform excellent customisation work. Therefore, aligning the decision of order selection and prioritisation (TD1) with strategic customers has a potential impact on building capabilities in focussed areas. 
Targeting less customers that generate most of the sales makes the overall commonalities in demand grow at a faster pace than uniqueness (Bozarth et al. 2009). This increases the firm's efficiency and flexibility to process orders. Such settings provide prerequisites to win more suitable orders and reduce the total number of orders that must be processed. This eventually leads to higher win-rates. As such, order selection and prioritisation (TD1) have a potential impact to make DS balancing easier, especially when ETO markets are booming and choices should be made to avoid over- and under-capacity, as shown in Figure 4.

\subsubsection{Reducing and absorbing SC complexity constraining} DS balancing through decisions related to supply capacity. Findings suggest that reducing the complexity stemming from supply can be done through ensuring proper selection of external contributors (TD7) and allocation of resources to order customisation (TD2). According to Potts and Ankrah (2014), external contributors like suppliers and subcontractors can make or break projects in the construction industry since their contributions often represent up to $80 \%$ of the total work. As the total supply base grows, the coordination required regarding supplier relationship management increases (Bozarth et al. 2009). Higher informationprocessing capacity is needed to absorb such complexity. This means that selecting suppliers (TD7) appropriately can potentially reduce SC complexity.

In general, coordination represents the essence of tacticallevel planning processes towards DS balancing (Oliva and Watson 2011). Any increase in coordination, either due to increased dynamic (that requires extra information-processing capacity to address increased uncertainties) or structural complexity (e.g. growing numbers of tasks and communication entities) needs a proportional increase in supply productivity to balance demand. This is possible either through utilising resources more efficiently, or simply through acquiring extra capacity (Hans et al. 2007). Within a tactical-level process domain, allocating resources to order customisation (TD2) is crucial for ensuring efficient critical resource utilisation.

Critical capacity provides the competitive advantage to win orders in ETO SCs (Cooper and Budd 2007). Findings show that increasing the critical resource utilisation efficiency is achieved by allocating individuals with high coordination competences to the right customer orders that make best use of their skillsets. Doing so can enable greater overall complexity absorption. Ventroux, Marle, and Vidal (2018) also suggested reshuffling of project organisations to facilitate absorbing and reducing complexity through intensifying interactions associated with critical decisions and activities.

As discussed by Bozarth et al. (2009), including more external contributors entails higher risks of disturbing internal manufacturing schedules, long and unreliable lead times and increased supply base globalisation with more cross-border uncertainties. Therefore, minimising the overall number of external contributors and, at the same time, increasing the representativeness of the local and most reliable and efficient ones should unsurprisingly entail less structural and dynamic complexity. Minimising the overall number of external contributors represents a form of decoupling practice since relying on less actors implies having fewer overall constraints and dependencies. According to Fernández Campos, Trucco, and Huaccho Huatuco (2019, 619), 'decoupling practices mitigate the negative impact of external SC complexities on SC performance'.

While this is a favourable setting in theory, some ETO contexts show that centralising supplier selection is challenging in practice. For instance, in the Swedish housing sector, critical site managers share significant project responsibility and, thus, stipulate the freedom of selecting suppliers. Companies sometimes have no options but to select foreign external contributors due to the possibility of gaining cost and technical benefits, which requires extra coordination, not only due to regulation differences, but also due to crosscultural and language barriers. Likewise, external contributors, whose planning and controlling systems are different and incompatible, or whose contributions cause unexpected absenteeism of internal labour and stoppages of machines, are also undesirable options. Such circumstances increase the overall SC complexity. The external contributor inputs (e.g. material quality) that cause instability of internal manufacturing cannot be directly captured by classic lead time management. This, in turn, increases coordination according to findings and previous works (e.g. Bozarth et al. 2009). The intensity of such coordination increases in ETO settings that lack the option of final product inventories as external contributors have extra pressure on timeliness (Olhager 2010).

\subsubsection{Reducing and absorbing SC complexity by DS bal-} ancing: multi-project optimisation. Order review is an important stage as information gathered about the contributions associated with parallel orders allows for comprehensive evaluations leading to changes on designs and plans (TD8) as opposed to sub-optimisations. Multiple-project optimisation aims at developing an aggregate (tactical) plan in which product and manufacturing process designs maximise synergies among resources and minimise compromises across the parallel ongoing and upcoming orders. Given a complexity setting where customer demand and supply capacity remain stable, such optimisation provides compensatory supply augmentation to recover from under-capacity states (Figure 4).

DS balancing using multi-project optimisation has the same complexity-absorbing and complexity-reducing impacts as several tactical-level decisions, as it reiterates the respective decision making considering fewer feasible options limited to narrow modifications in individual project plans. For instance, viewing product and manufacturing designs and delivery plans across orders allow for suggesting alternative materials, geometrics and methods that maximise resource utilisation and minimise risks to accept more demand, i.e. absorb more complexity. An example of a complexity-reducing impact is excluding less profitable risky orders, and refining designs and plans to minimise unnecessary details and uncertainties.

Finally, due to the embedded heterogeneity between order decoupling categories in the ETO SCs, the risks related 
to inadequate safety, quality, publicity, cost and time vary across customer orders. Therefore, findings suggest that balancing demand and supply requires proper risk distribution through, for instance, adapting product designs and manufacturing processes to the capability of the available capacity, including less novelty (uniqueness) and detail (number of parts). More experienced (and often critical) competences should be allocated to riskier projects. Similarly, the type of external parties that must be involved should be aligned with available resource capabilities. Dealing with new and global suppliers that have long and less reliable lead times as well as less compatibility requires proper experience. Therefore, such suppliers should be matched with projects where more qualified resources are allocated or vice versa.

\section{Concluding remarks}

\subsection{Contributions to theory and practice}

As a response to the first part of the research question, a main contribution of this study is the identification of key tactical-level planning activities and decisions that have an impact on the complexity constraining DS balancing in an ETO setting. Previous works (e.g. Hans et al. 2007; Adrodegari et al. 2015; Carvalho, Oliveira, and Scavarda 2015) lack clear demarcations of integrated tactical-level planning activities and decisions which serve as a basis for advancing planning systems. This synthesises a conceptual framework of tactical planning in ETO settings (Figure 1) as a guiding reference to develop a detailed framework (Figure 3) using empirical data from an ETO-oriented company. The framework has managerial implications and may support related practitioners in developing or mapping a more ETO contextspecific, structured and transparent planning process to balance demand and supply considering multiple projects.

This study elaborates on the crucial role of three main activities in DS balancing: 1 . selecting and prioritising customer orders, 2. selecting external contributors and 3. multiproject optimisation.

The relevance of these activities stems from the impact of the underlying decisions on DS balancing (TD1, TD2, TD7 and TD8). This study uses the dimensions of structural and dynamic complexity, adapted from Senge (1998), and the SC complexity drivers and ETO variables, from the works of Bozarth et al. (2009) and Cannas et al. (2020), respectively, to analyse the impact of tactical-level planning activities and decisions. Therefore, this study further contributes to SC complexity-reducing and complexity-absorbing practices. The findings provide additional evidence, in a different ETO context and with higher level of observational detail, to support two propositions set forth by Fernández Campos, Trucco, and Huaccho Huatuco (2019). As such, findings explain how tactical-level decision making can serve as both varietyreducing and variety-decoupling practices.

Another area of practical implication corresponds to construction management. Findings show that the decisions within order selection and prioritisation, and multi-project optimisation need IT support that enables accumulating inputs from external sources and previous projects, allows for seamless information processing, and more comprehensive and robust scenario-based analysis. This helps in identifying the potential medium-term consequences of the decisions on capacity.

\subsection{Limitations and future research}

One major limitation of this study concerns the circumscribed generalisability of findings due to the single-case study design adopted. Since tactical planning in ETO environments lacks fundamental understanding of related process activities and decisions, an in-depth analysis utilising empirical data was preferable to sample breadth. The study addressed a single order fulfilment process that tackles customer enquiries corresponding to six decoupling configurations on the 2D-COD matrix suggested by Cannas et al. (2019). Future efforts may benefit from the proposed reference process framework (Figure 3) to conduct a multiple case study that covers more order fulfilment processes and other 2D-COD configurations. Future research may also compare the framework with established S\&OP processes in ETO environments to further explore the prerequisites of DS balancing in such complex settings. In this respect, studying the integration (coordination) mechanisms related to DS balancing is recommended since both processes need intensive cross-functional interactions to address medium-term planning problems.

Previous construction management studies focussed on contextual variables that are important for tactical planning in the construction industry. Findings suggest that the processing durations of critical engineering competences within tendering and execution are contingent upon how they are assigned. Although general construction contractors want to select orders that maximise the utilisation of individuals with critical competences, they often fail to identify the individuals' potential multifaceted utilisations. Therefore, modelling and optimisation studies may address the possibilities to equivalently combine various seniority levels and skillsets without compromises. Modelling such flexibility helps to improve RCCP in general (Hans et al. 2007), and order selection in particular. Such optimisation may consider options based on critical and non-critical resource availability and configurability.

The analytical approach adopted calls for further explicative research. The conceptualisation of complexity to expand the understanding of tactical-level decisions' impact on DS balancing lacks support from operations management literature. The impact on DS balancing is claimed through empirical evidence suggesting that decisions may increase or reduce the associated structural and dynamic complexity. However, this approach does not provide insights into how much the complexity will increase, or decrease, so that decisions can be ranked in terms of their influence on complexity.

Finally, inferring the decision impacts on structural and dynamic complexity was based on empirical evidence showing changes on details (at both process and SC levels) and uncertainties, respectively. Such an approach limits the study's findings since structural and dynamic complexity are broader concepts. 


\section{Acknowledgements}

The authors would like to thank the representatives of the participating companies and construction management researchers for their contribution to the protocol revision and subsequent data collection.

\section{Disclosure statement}

No potential conflict of interest was reported by the author(s)

\section{Funding}

This work was supported by Vinnova under [Grant 2015-04322].

\section{Notes on contributors}

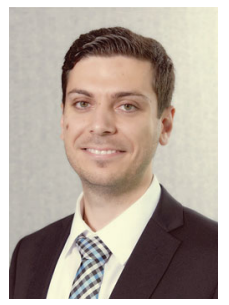

Hafez Shurrab holds a degree of licentiate of engineering. He studies the demand-supply balancing effect of tactical-level planning processes, focussing on three interfaces in complex settings. For the strategic-tactical interface, the focus is on customer order fulfilment, while for the tactical interface, the focus is on sales and operations planning. Both interfaces address engineer-to-order markets. For the tactical-operational interface, the focus is on the schedule instability of automakers.

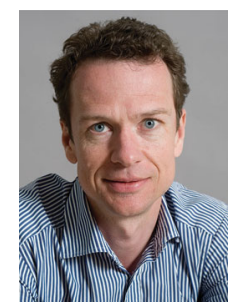

Patrik Jonsson is a professor of Operations and Supply Chain Management at Chalmers University of Technology. He gained his Ph.D. in production management from Lund University. His research interests are in the fields of operations and supply chain planning, with a specific interest in the generation of demand and supply coordination in firms and supply chains through data- and technology-enabled operations and planning processes (e.g. demand management and sales and operations planning).

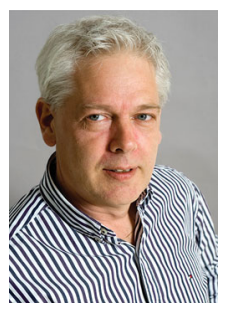

Mats I. Johansson is a professor in logistics and supply chain management at Chalmers University of Technology. He holds a MSc degree in mechanical engineering and $\mathrm{aPh}$ degree in transportation and logistics within the area of product design, focussing on logistics performance in mixed-model production environments. His research interests include development, planning, and control of materials supply and distribution systems including underlying supporting information systems and methods for evaluating competitiveness and resource consumption.

\section{ORCID}

Hafez Shurrab (iD http://orcid.org/0000-0002-6897-7227

Patrik Jonsson (iD http://orcid.org/0000-0002-9457-5854

Mats I. Johansson (iD http://orcid.org/0000-0001-5074-1737

\section{References}

Adrodegari, F., A. Bacchetti, R. Pinto, F. Pirola, and M. Zanardini. 2015. "Engineer-to-Order (ETO) Production Planning and Control: An Empirical Framework for Machinery-Building Companies." Production Planning \& Control 26 (11): 910-932. doi:10.1080/09537287.2014. 1001808.
Aitken, J., C. Bozarth, and W. Garn. 2016. "To Eliminate or Absorb Supply Chain Complexity: A Conceptual Model and Case Study." Supply Chain Management: An International Journal 21 (6): 759-774. doi:10.1108/ SCM-02-2016-0044.

Alfieri, A., T. Tolio, and M. Urgo. 2011. "A Project Scheduling Approach to Production Planning with Feeding Precedence Relations." International Journal of Production Research 49 (4): 995-1020. doi:10. 1080/00207541003604844.

Bertrand, J., and D. Muntslag. 1993. "Production Control in Engineer-toOrder Firms." International Journal of Production Economics 30: 3-22.

Birkie, S. E., and P. Trucco. 2016. "Understanding Dynamism and Complexity Factors in Engineer-to-Order and Their Influence on Lean Implementation Strategy." Production Planning \& Control 27 (5): 345-359.

Bozarth, C. C., D. P. Warsing, B. B. Flynn, and E. J. Flynn. 2009. "The Impact of Supply Chain Complexity on Manufacturing Plant Performance." Journal of Operations Management 27 (1): 78-93. doi: 10.1016/j.jom.2008.07.003.

Cannas, V. G., J. Gosling, M. Pero, and T. Rossi. 2019. "Engineering and Production Decoupling Configurations: An Empirical Study in the Machinery Industry." International Journal of Production Economics 216: 173-189. doi:10.1016/j.jpe.2019.04.025.

Cannas, V. G., J. Gosling, M. Pero, and T. Rossi. 2020. "Determinants for Order-Fulfilment Strategies in Engineer-to-Order Companies: Insights from the Machinery Industry." International Journal of Production Economics 228: 107743. doi:10.1016/j.ijpe.2020.107743.

Carvalho, A. N., F. Oliveira, and L. F. Scavarda. 2015. "Tactical Capacity Planning in a Real-World ETO Industry Case: An Action Research." International Journal of Production Economics 167: 187-203. doi:10. 1016/j.ijpe.2015.05.032.

Cay, F., and C. Chassapis. 1997. "An IT View on Perspectives of Computer Aided Process Planning Research." Computers in Industry 34 (3): 307-337. doi:10.1016/S0166-3615(97)00070-5.

Carvalho, C., T. McGovern, and C. F. Earl. 2001. "A Typology of UK Engineer-to-Order Companies." International Journal of Logistics Research and Applications 4 (1): 43-56. doi:10.1080/13675560110038068.

Cooper, M. J., and C. S. Budd. 2007. "Tying the Pieces Together: A Normative Framework for Integrating Sales and Project Operations." Industrial Marketing Management 36 (2): 173-182. doi:10.1016/j. indmarman.2006.03.005.

Day, G. S. 1994. "The Capabilities of Market-Driven Organizations." Journal of Marketing 58 (4): 37-52. doi:10.1177/002224299405800404.

Dubois, A., and L.-E. Gadde. 2002. "The Construction Industry as a Loosely Coupled System: implications for Productivity and Innovation." Construction Management \& Economics 20 (7): 621-631.

Earl, C., D. P. Song, and C. Hicks. 2003. "Planning Complex Engineer-toOrder Products." In Recent Advances in Integrated Design and Manufacturing in Mechanical Engineering, edited by Grigore Gogu, Daniel Coutellier, Patrick Chedmail and Pascal Ray, 463-472. Berlin: Springer.

Fernández Campos, P., P. Trucco, and L. Huaccho Huatuco. 2019. "Managing Structural and Dynamic Complexity in Supply Chains: insights from Four Case Studies." Production Planning \& Control 30 (8): 611-623.

Fleischmann, B., and H. Meyr. 2003. "Planning Hierarchy, Modeling and Advanced Planning Systems." In Supply Chain Management: Design, Coordination and Operation, Handbooks in Operations Research and Management Science, edited by A. G. De Kok and S. C. Graves, 455-523. Amsterdam: Elsevier.

Flick, U. 2009. An Introduction to Qualitative Research. CA: SAGE Publications.

Gademann, N., and M. Schutten. 2005. "Linear-Programming-Based Heuristics for Project Capacity Planning." IIE Transactions 37 (2): 153-165.

Galbraith, J. R. 1977. Organization Design. Boston: Addison-Wesley Longman Publishing Company.

Giebels, M. M. T. 2000. "EtoPlan: A Concept for Concurrent Manufacturing Planning and Control." PhD diss., University of Twente.

Giesberts, P. M., and L. V. D. Tang. 1992. "Dynamics of the Customer Order Decoupling Point: impact on Information Systems for Production Control." Production Planning \& Control 3 (3): 300-313. 
Gosling, J., B. Hewlett, and M. M. Naim. 2017. "Extending Customer Order Penetration Concepts to Engineering Designs." International Journal of Operations \& Production Management 37 (4): 402-422.

Gosling, J., and M. M. Naim. 2009. "Engineer-to-Order Supply Chain Management: A Literature Review and Research Agenda." International Journal of Production Economics 122 (2): 741-754. doi:10. 1016/j.ijpe.2009.07.002.

Gosling, J., D. R. Towill, M. M. Naim, and A. R. Dainty. 2015. "Principles for the Design and Operation of Engineer-to-Order Supply Chains in the Construction Sector." Production Planning \& Control 26 (3): 203-218.

Grimson, J. A., and D. F. Pyke. 2007. "Sales and Operations Planning: An Exploratory Study and Framework." The International Journal of Logistics Management 18 (3): 322-346. doi:10.1108/09574090710835093.

Hans, E. W., W. Herroelen, R. Leus, and G. Wullink. 2007. "A Hierarchical Approach to Multi-Project Planning under Uncertainty." Omega 35 (5): 563-577. doi:10.1016/j.omega.2005.10.004.

Hicks, C., T. McGovern, and C. F. Earl. 2000. "Supply Chain Management: A Strategic Issue in Engineer to Order Manufacturing." International Journal of Production Economics 65 (2): 179-190. doi:10.1016/S09255273(99)00026-2.

Hoekstra, S., and J. Romme. 1992. Integral Logistic Structures: developing Customer-Oriented Goods Flow. New York, NY: Industrial Press Inc.

Jonsson, P., and J. Holmström. 2016. "Future of Supply Chain Planning: closing the Gaps between Practice and Promise." International Journal of Physical Distribution \& Logistics Management 46 (1): 62-81.

Kjellsdotter Ivert, L., and P. Jonsson. 2014. "When Should Advanced Planning and Scheduling Systems Be Used in Sales and Operations Planning?" International Journal of Operations \& Production Management 34 (10): 659-681.

Kristensen, J., and P. Jonsson. 2018. "Context-Based Sales and Operations Planning (S\&OP) Research: A Literature Review and Future Agenda." International Journal of Physical Distribution \& Logistics Management 48 (1): 19-46.

Nobibon, F. T., R. Leus, K. Nip, and Z. Wang. 2015. "Resource Loading with Time Windows." European Journal of Operational Research 244 (2): 404-416.

Olhager, J. 2010. "The Role of the Customer Order Decoupling Point in Production and Supply Chain Management." Computers in Industry 61 (9): 863-868. doi:10.1016/j.compind.2010.07.011.

Olhager, J., M. Rudberg, and J. Wikner. 2001. "Long-Term Capacity Management: Linking the Perspectives from Manufacturing Strategy and Sales and Operations Planning." International Journal of Production Economics 69 (2): 215-225. doi:10.1016/S0925-5273(99)00098-5.

Oliva, R., and N. Watson. 2011. "Cross-Functional Alignment in Supply Chain Planning: A Case Study of Sales and Operations Planning." Journal of Operations Management 29 (5): 434-448. doi:10.1016/j.jom. 2010.11.012.

Pereira, D. F., J. F. Oliveira, and M. A. Carravilla. 2020. "Tactical Sales and Operations Planning: A Holistic Framework and a Literature Review of Decision-Making Models." International Journal of Production Economics 228: 107695. doi:10.1016/j.ijpe.2020.107695.

Potts, K., and N. Ankrah. 2014. Construction Cost Management: learning from Case Studies. Abingdon: Routledge.

Rauch, E., P. Dallasega, and D. T. Matt. 2018. "Complexity Reduction in Engineer-to-Order Industry Through Real-Time Capable Production Planning and Control." Production Engineering 12 (3-4): 341-352. doi: 10.1007/s11740-018-0809-0.

Sabolová, M., and M. Tkáč. 2015. "Characterization of Procurement Process in the Construction Company." Investment Management and Financial Innovations: International Research Journal 12: 166-170.

Senge, P. M. 1998. "The Leader's New Work: Building Learning Organizations." In Leading Organizations: Perspectives for a New Era, edited by G. R. Hickman, 439-457. California, CA: SAGE Publications.

Serdarasan, S. 2013. "A Review of Supply Chain Complexity Drivers." Computers \& Industrial Engineering 66 (3): 533-540.

Shurrab, H., P. Jonsson, and M. I. Johansson. 2020. "Managing Complexity through Integrative Tactical Planning in Engineer-to-Order Environments: Insights from Four Case Studies." Production Planning \& Control doi:10.1080/09537287.2020.1837937.
Stake, R. E. 2000. "The Case Study Method in Social Inquiry." In The American Tradition in Qualitative Research, edited by Norman Kent Denzin and Yvonna Sessions Lincoln, 130-138. California, CA: SAGE Publications.

Turner, N., J. Aitken, and C. Bozarth. 2018. "A Framework for Understanding Managerial Responses to Supply Chain Complexity." International Journal of Operations \& Production Management 38 (6): 1433-1466.

Ventroux, J., F. Marle, and L.-A. Vidal. 2018. "Organizational Reshuffling to Facilitate Coordinated Decisions in Complex Projects." Concurrent Engineering 26 (3): 299-309. doi:10.1177/1063293X18756718.

Weber, F., C.-A. Dalluege, T. Shamsi, and M. Franco. 2000. "Improving Bid Preparation in Supply Chains in the Construction Industry." Journal of e-Business Strategy Management 1 (3): 183-193.

Wikner, J., and M. Rudberg. 2005. "Integrating Production and Engineering Perspectives on the Customer Order Decoupling Point." International Journal of Operations \& Production Management 25 (7): 623-641.

Yin, R. K. 2017. Case Study Research: Design and Methods. California, CA: SAGE Publications.

\section{Appendix 1. Interview protocol}

1. Personal background

1.1. Can you tell us a little about your educational background and previous experience?

1.2. How long have you been with SGC? In what which positions and capacities?

1.3. What is your current position and what are your main responsibilities?

2. Functional area

2.1. Given that you work for this functional area, what are the main functions and responsibilities of the functional area?

2.2. What do you consider are the main objectives of that functional area?

2.3. What are the main objectives of the functional area in relation to the bid preparation process?

2.4. If not clear already, what are the processes that you follow to fulfil the responsibilities? What contributions do you need and which decisions do you need to make? How are your results communicated and coordinated? To the extent that you can tell, how is this process different from the processes of other functions in the organisation?

3. The bid preparation process

3.1. Based on your understanding, describe how the bid preparation process at present is executed. What activities are included? For each of the activities,

3.1.1. What is the rationale for that activity: Why does SGC do that? What is it that the process is trying to achieve?

3.2. How do you participate in the bid preparation process? For each activity,

3.2.1. What is the rationale for that activity: Why do you do, or are required to do, that?

3.2.2. What is the intentionality of that activity: what are you trying to achieve by performing that activity? What are your goals relating to influencing the process?

3.3. The re-planning meetings seem to play a significant part in determining the outcome of the bid preparation process, and the discussion during those meetings seems to be open-ended and very fluid, how do you attempt to influence the outcomes of the meeting and which decisions must be made during these meetings?

4. Follow-up

4.1. Is there anything else to tell as to be aware of how the bid preparation process is working and your interactions with the othe functional areas?

4.2. Is there anyone else you recommend us to contact so as to get a better understanding of the objectives and inner workings of the bid preparation process?

4.3. Could we contact you in the future for clarification questions in case some gaps or inconsistencies pop up from our notes? 